\title{
Investigación \\ El cine, lugar de encuentro entre las artes
}

Jorge Gorostiza

Escritor y arquitecto

\section{Resumen}

El cine, arte o industria. Un debate paralelo a la historia del cine, una forma de expresión de naturaleza distinta que modificó el concepto de arte. Más allá del cine como arte total y autónomo, Gorostiza describe en este articulo las múltiples y diversas relaciones existentes entre cine y arte desde sus origenes. Se analiza el cine como espacio creativo donde convergen las diversas disciplinas artísticas (pintura, escultura...); un espacio frecuentado por artistas plásticos a lo largo de su historia; un espacio de representación del patrimonio; un espacio generador de patrimonio. Un espacio patrimonio. El séptimo arte, único y diferente.
En 1911 Ricciotto Canudo usó por primera vez el afortunado y pertinaz calificativo "séptimo arte" aplicado al cine. En su Manifeste des Sept Arts escribió: "hoy, el círculo en movimiento de la estética se cierra triunfalmente en esta fusión total de las artes Ilamada Cinematógrafo" (CANUDO, 1923:2). El cine para él era la concentración de lo que hasta el momento se habian considerado las seis artes: arquitectura, pintura, escultura, música, danza y poesía. Era el arte total, aquél por el que abogaba Richard Wagner el siglo anterior, "necesitamos al cine para crear el arte total al que, desde siempre, han tendido todas las artes" (CANUDO, 1923:2).

Para Canudo y otros teóricos incluir al cine entre las artes, de un modo ingenuo y optimista, servía sobre todo para reivindicar el espectáculo que había comenzado como una atracción más en las barracas de feria, logrando equipararlo con las más ilustres manifestaciones artísticas, de ese modo se ensalzaba y conse guía un estatus del que carecía hasta ese momento. La importancia de esta reivindicación también la percibían los cineastas y aún más los incipientes empresarios dedicados a la exhibición, que deseaban difundir sus películas entre círculos cada vez más amplios y cultos. Recuérdese que el cine no le interesaba a amplios sectores de la sociedad de tendencias conservadoras, por ejemplo el abuelo de Jean-Paul Sartre que se quedó perplejo al saber que su nieto iba al cinematógrafo (GEDULD, 1981:56), y el nuevo espectáculo incluso les escandalizaba, como le sucedió a Maximo Gorki cuando descubrió que la imagen de una hija pequeña de Lumière se proyectaba en un local frecuentado por prostitutas (GEDULD, 1981:17).

Fueron los más jóvenes quienes pronto se quedaron fascinados y descubrieron el potencial del nuevo medio expresivo. Pocos años después del texto de Canudo los futuristas planteaban la ya famosa "fórmula": "Pintura + escultura + dinamismo plástico + palabras en libertad + entonarruidos + arquitectura + teatro sintético = Cinematografía futurista" (MARINETTI, 1916:24). El cine ya era otra más de las artes, pero además las películas vanguardistas debian ser la adición de varias de aquellas artes. Los miembros de este grupo en ese mismo manifiesto escribian: "el cinematógrafo es un arte en sí mismo. El cinematógrafo, por tanto, jamás debe copiar a escenario. El cinematógrafo, al ser profundamente visual, deberá llevar a cabo principalmente el proceso de la pintura: distanciarse de la realidad, de la fotografía, de lo delicado y de lo solemne. Llegar a ser antidelicado, deformante, impresionista, sintético, dinámico, verbo-libre" (MARINETTI, 1916:21). Se comenzaba a reconocer la especificidad fílmica. El cine no debía reproducir, sino crear.

Efectivamente, en 1916 Hugo Münsterberg en The Photoplay: A Psychological Study planteó que "si estamos de acuerdo que el propósito del arte, comprendido el dramático, no sea una imitación de la vida, sino su transformación completa, se abre para el 


\section{Investigación}

El cine, lugar de

encuentro entre las artes

Jorge Gorostiza

cine una perspectiva totalmente nueva" (MÜNSTERBERG, 1980 87). Veinte años después, Walter Benjamin planteó en La obra de arte en la época de la reproductibilidad técnica, que el cine modifica el concepto de arte y sus categorías, no hay que identificar o adecuar el cine al sistema del arte, sino volver a formular el concepto de arte debido a la aparición de un nuevo medio que antes no existía.

No cabe en este artículo una discusión más amplia y a veces bizantina, sobre la pertenencia del cine al campo artístico, la técnica o la industria. Lo que interesa es entenderlo como un punto donde se dan cita las diversas disciplinas artísticas, relacionándolo con el patrimonio.

Desde los años veinte del siglo pasado el cine se convirtió en un campo de experimentación de pintores, escultores e incluso arqui tectos, cuando descubrieron que era un instrumento con el que podian expresarse tan bien como con los pinceles o los cinceles. Ya se vio la importancia que le daban los futuristas, en un breve resumen se puede citar Anémic cinéma (1923) y Ballet mécanique (1924) realizadas respectivamente por Marcel Duchamp y Fernand Léger; Le retour à la raison (1923), Emak-Bakia (1926), L'Étoile de mer (1928) y Les mystères du châteu de Dé (1929) dirigidas por Man Ray y la última rodada dentro de un edificio del arquitecto Robert Mallet-Stevens, quien con Léger, Jean Lurçat, Paul Poiret y Pierre Chareau, creó los decorados de La inhumana (L'Inhumaine, Marcel L'Herbier, 1923); el guión de Entr'acte (1924) escrito por Francis Picabia; el vestuario y los decorados de Sonia Delaunay para Le P'tit Parigot (René Le Somptier, 1926) en la que los cuadros eran de su marido Robert, Albert Gleizes y André Lhote. Esto en lo que respecta a conocidos pintores, si se habla de composi tores hay que nombrar a Darius Milhaud, que empezó a trabajar en el cine en 1916 y escribió una partitura para la antes citada película muda La inhumana, otros músicos que compaginaron sus labores cinematográficas con las propias de su profesión fueron Georges Auric, Benjamin Britten, Aaron Copland, Paul Hindemith, Arthur Honegger, Jacques Ibert, Sergei Prokofiev, Ralph Vaughn Williams y William Walton. En cuanto a la literatura, la intervención de reputados escritores en el cine es muy conocida, baste citar la desafortunada experiencia de Francis Scott Fitzgerald y William Faulkner, y como contraposición los interesantes trabajos de Jean Cocteau y más recientemente de David Mamet.

En España la nómina de artistas plásticos que intervinieron en el cine es bastante menos significativa, pero es imposible dejar de citar la experiencia de Salvador Dalí en Un chien andalou (1929) y L'âge d'or (1930), asi como sus trabajos posteriores en la industria cinematográfica estadounidense en las secuencias oníricas de Recuerda (Spellbound, Alfred Hitchcock, 1945) y El padre de la novia (Father of the Bride, Vincente Minnelli, 1950); la labor fecunda de José Luis Galicia como director artístico y de José Caballero como escenógrafo y figurinista; y las más esporádicas de Alberto
Corazón, José Hernández, Gustavo de Maeztu, Manuel Mampaso y Pere Pruna. Respecto a los compositores; Ernesto Halffter compuso la música un tanto excesiva y fuera de lugar de Don Quijote de la Mancha (Rafael Gil, 1948) y otras como las de La señora de Fátima (Rafael Gil, 1951) y La princesa de Éboli / That Lady (Terence Young, 1954); Luis de Pablo tuvo una feliz colaboración con Carlos Saura en La caza (1965), La madriguera (1968), Ana y los lobos (1971), El jardín de las delicias (1969) y La prima Angélica (1974), y sobre todo es interesante su ajustada partitura para El espíritu de la colmena (Victor Erice, 1973). No se debe olvi dar que también hubo arquitectos que intervinieron en el cine español, como Nemesio Sobrevila ${ }^{1}$ y Luis M. Feduchi, además hubo otros que trabajaron esporádicamente como Pedro Muguruza, Arniches y Domínguez; otros compaginaron su activi dad proyectando y construyendo edificaciones con la cinematográfica, como Antonio Labrada, Manuel Infiesta y José Pellicer estos dos últimos bajo las órdenes del peculiar Ignacio F. Iquino; incluso hubo algunos cuyos nombres figuran en los títulos de crédito de varias películas, pero se duda mucho que trabajaran en ellas, como es el caso de José Antonio Coderch².

\section{Protección}

A efectos prácticos muchas veces un bien, sobre todo si es un edificio o un conjunto de ellos, sin demasiado valor intrínseco como monumento, se cataloga para evitar que desaparezca, protegiéndolo de la especulación y el desarrollismo de nuestra sociedad capitalista, en la que priman valores crematísticos sobre los culturales o artísticos.

Uno de los ejemplos de estos edificios amenazados es precisamente el de los grandes cinematógrafos construidos desde los años veinte por todo el mundo y que ahora han sido demolidos, cambiado su uso transformándolos en supermercados o bingos, y si sobreviven proyectando películas, mutilados y troceados, compartimentados en molestas minisalas que cumplen con dificultad sus funciones.

Si los edificios han de ser protegidos, el cine también debe ser defendido de los que Raymond Borde llama "derechohabientes" (BORDE, 1991: 11), aquellos que ostentan y a veces detentan los derechos de las películas. El caso más conocido y uno de los recientes es el del magnate navegante Ted Turner que, como se recordará, adquirió gran parte del catálogo de la Warner Bros. y decidió colorear por medios electrónicos una serie de películas Su decisión, que fue muy controvertida, afortunadamente no afectó a los negativos ni a las copias que obraban ya en las fit motecas y lo peor de todo, además de distorsionar un producto creado de otra manera y en otras condiciones, fue el mal gusto de los técnicos que eligieron los colores, ni la persona más incut ta hubiese elegido unas combinaciones de tonos tan nefastas, 

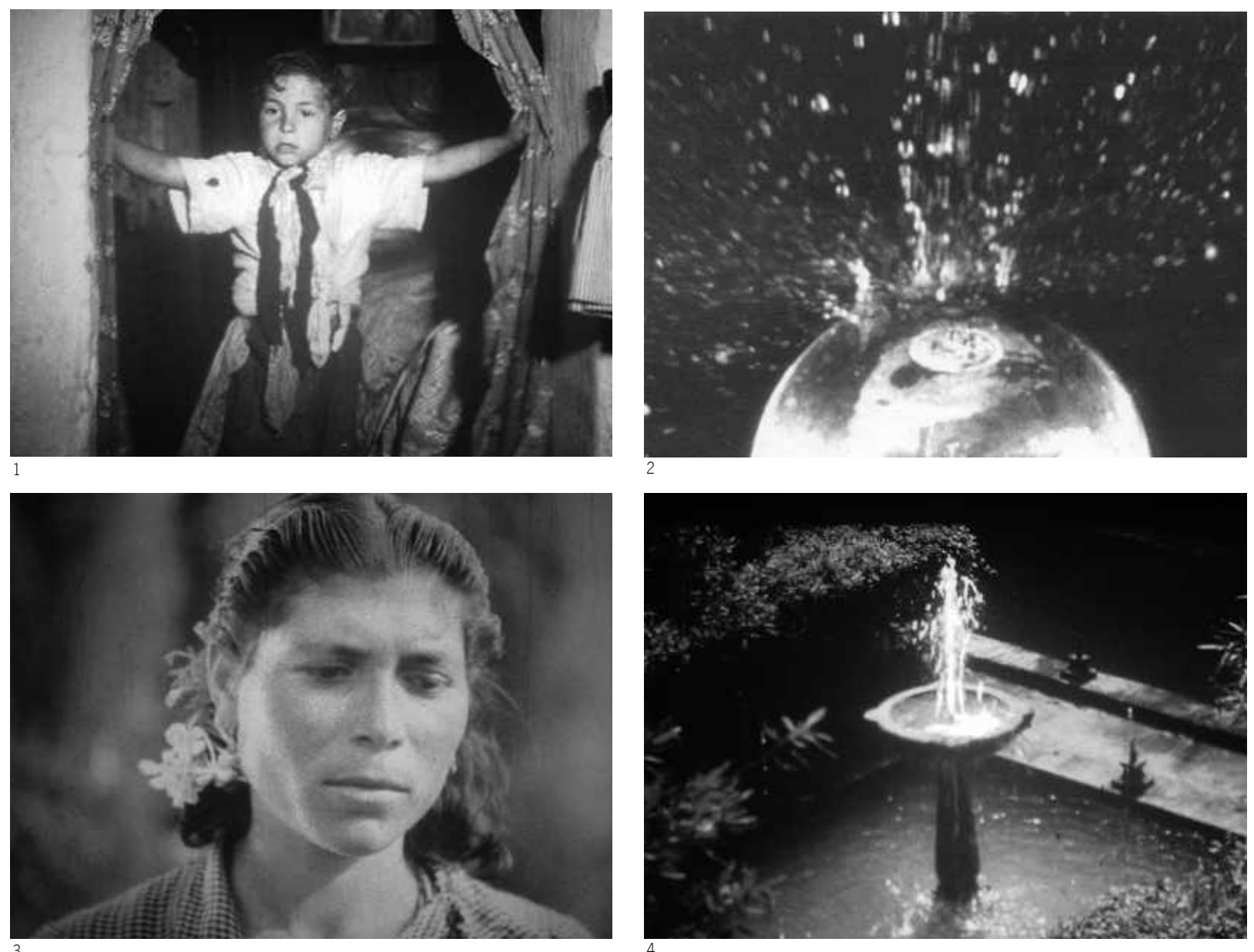

como las que le endilgaron al vestuario de muchos de los intérpretes de aquellos años.

\section{El cine patrimonio}

El cine y el patrimonio fundamentalmente se relacionan de dos formas. La primera, porque el cine en sí mismo es un patrimonio como manifestación cultural encuadrada en un momento histórico determinado. En este mismo número de $\mathrm{PH}$ hay otros artículos centrados en este tema, por lo que sólo se quería aportar una breve acotación. Un edificio o un objeto cuando se declara como monumento es único, sin embargo, en el cine hay un soporte físi co, la cinta de celuloide, que admite numerosas copias y que se proyecta sobre una pantalla, hay por tanto un doble patrimonio: el negativo original y aquello inmaterial que ven los espectadores cuando se proyecta. Esto último, que es más importante, puede estar hoy en dia en otro soporte como el DVD, con mejor calidad que muchas copias en $35 \mathrm{~mm}$. Algo parecido pasa con la música en la que una única partitura u obra escrita tiene múltiples interpretaciones, por lo que habrían de protegerse además reproducciones de determinados conciertos.

En este tema de la protección hay otra peculiaridad, que se refiere a los espacios de rodaje. Es decir, la posibilidad de preservar los decorados donde se rodaron algunas películas importantes. Como se sabe, en la época de los grandes estudios había una serie de elementos que se reutilizaban en varias cintas, mientras otros se desmontaban o destruian ${ }^{3}$, como la gigantesca puerta de King Kong (King Kong, Ernest B. Schoedsock y Merian C. Cooper, 1933) que fue quemada para simular el incendio de Atlanta en Lo que el viento se llevó (Gone with the Wind, Victor Fleming, 1939), hoy en día algunos de estos espacios se han reproducido en los parques

temáticos que se encuentran en estudios como los de la Universal Estos espacios en la realidad tienen a veces poco que ver con el que se ve proyectado en las pantallas, porque el objetivo de una cámara no es el ojo humano y los espacios se construían con perspectivas forzadas, con sus dimensiones reducidas o sólo en parte y eran completados después con técnicas de efectos especiales como el "matte painting", por eso no tiene mucho sentido declarar estos elementos escenográficos como patrimonio, si no es por pertenecer al patrimonio industrial cinematográfico, como sucede con cámaras, proyectores y otros objetos. Un patrimonio cuyo interés radica en conocer con qué materiales y técnicas se construian físicamente en otras épocas esos decorados. Un ejemplo es un fragmento de los "paneauxs" que configuraban la ciudad de El gabinete del doctor Caligari (Das Kabinet des Dr. Caligari, Robert Wiene, 1919), que se encontraban en el Museo del Cine situado en el Palacio de Chaillot parisino, un gran objeto que quizás no fuese el original delante del que se rodó la película, por lo que, si así fuera, perdería todo su interés como patrimonio, tal como le sucede a los espantosos y ridículos edificios "caligaristas" construidos en el parque temático de los estudios Babelsberg en Berlín.

\section{El patrimonio en el cine}

La segunda relación entre el cine y el patrimonio se produce por ser el cine un medio de comunicación visual, es decir, gracias a aquello que el cine muestra del patrimonio, por lo que aparece en las pantallas y queda fijado para siempre, gracias a las imágenes en movimiento.

Desde los años veinte hubo quien ya descubrió el poder de la ima gen móvil para difundir las nuevas manifestaciones artísticas. Uno de ellos fue el citado Mallet-Stevens quien escribió que el cine "debe 


\section{Investigación}

El cine, lugar de

encuentro entre las artes

Jorge Gorostiza

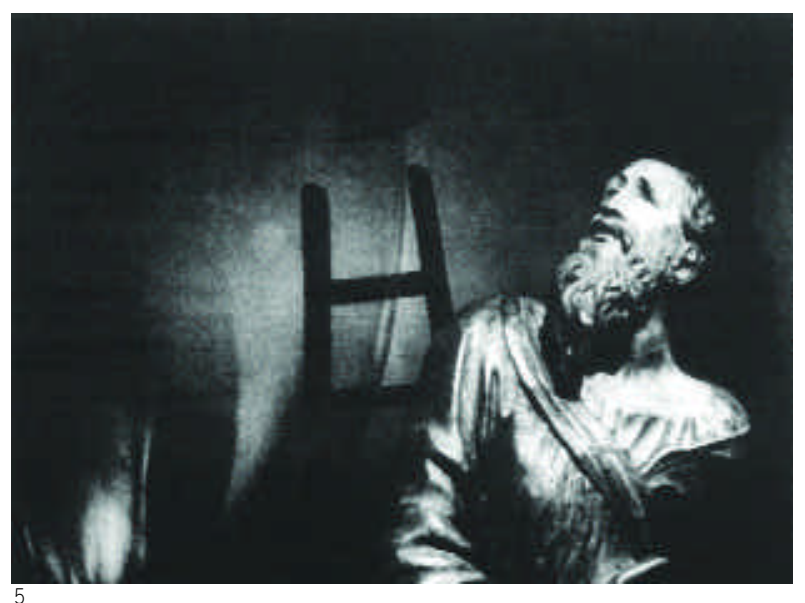

ser un instrumento de propaganda infinitamente superior a una exposición por muy visitada que sea. El cine llevará hasta el fin de los campos, a los paises más lejanos, las formas nuevas, la técnica nueva, el arte de hoy en dia; hará conocer y amar la arquitectura moderna, la arquitectura universal, la que se apoya en la lógica y el empleo juicioso de los nuevos materiales, arquitectura de orden y de método", deseando que "la propaganda magnífica del cine sirva más como medio de educación del público y menos como modelo a reproducir por los arquitectos" (MALLET-STEVENS, 1925). Es importante que además el arquitecto reconociese la influencia de los espacios cinematográficos en sus colegas de profesión.

El cine es un lugar en el que se reflejan las manifestaciones artísticas de dos formas diferentes. La primera y más inmediata se produce de un modo directo, gracias a los documentales o las películas con argumento rodadas en espacios naturales que no han sido modificados, donde se pueden ver directamente los edificios y objetos artísticos destruidos o modificados durante el siglo XX. Es obvio que esta forma de representación no es la realidad, sino sólo su imagen. La realidad en el cine y en las artes figurativas se construye, incluso en el caso de los noticiarios y documentales, lo que se ve en la pantalla está mediatizado por el punto de vista del cineasta. El objeto de las películas puede ser sólo el propio patrimonio, lo que sucede si se trata de docu mentales cuyo fin sea ese patrimonio, pero también esos elemen tos patrimoniales pueden aparecer como fondo o entorno de la acción si son cintas argumentales.

En la segunda forma de reflejarlas se recrean edificaciones, objetos artísticos y costumbres, que también han desaparecido, en las cintas con argumento. Una de cuyas variantes, es el de los "biopics" (contracción de las palabras inglesas biography y topics) de artistas que han existido en la realidad o de otros inventados, la narración de las vidas, casi siempre atormentadas, de pintores, músicos, arquitectos ${ }^{4}$, etc.

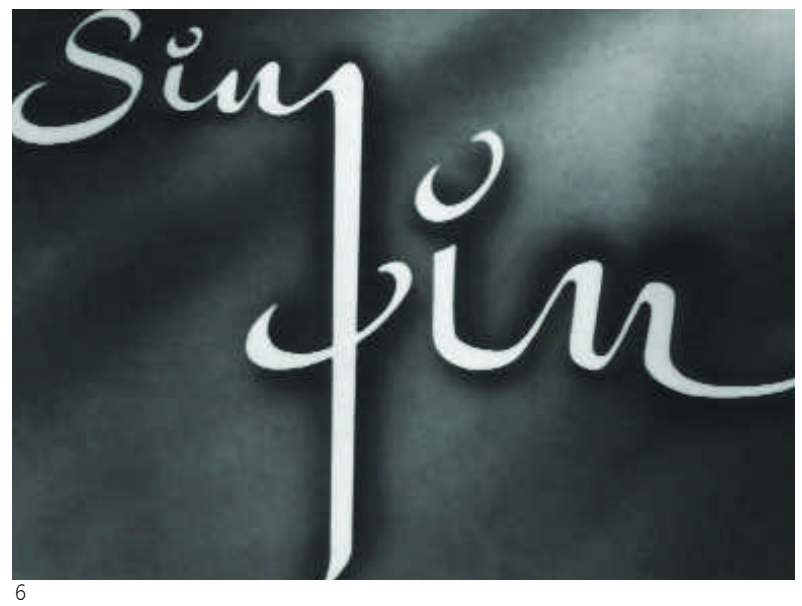

Las manifestaciones artísticas que se han representado en el cine abarcan toda la historia de la humanidad y no han sido objetivas o "científicas", sino que siempre han sido interpretaciones basadas en los conocimientos del momento histórico en que fue ron producidas las películas.

De hecho, muchos directores artísticos han dicho que lo difícil es representar el pasado reciente, Josep Rosell declaraba: "las peliculas actuales son más difíciles de hacer. La película histórica tiene sus dificultades, como encontrar los materiales y reproducir la época. Pero a nivel teórico, las actuales son mucho más difíciles. También hay directores de cine que lo dicen. El mismo Trueba asegura que en las películas de época tienes más libertad, y yo también lo digo hace años, porque no tienes distancia para valorar lo que estás haciendo. Incluso lo veo en mis películas de hace cinco o seis años, que transcurrían durante la época actual y, por ejemplo, le ponía en el despacho a un médico una mesa de diseño, porque era la explosión del disseny, ahora veo la película y a mí me causa risa ese despacho ¿Por qué? Porque no tenías distancia para valorarlo. Tampoco tienes elementos dónde buscar información. Si estás trabajando en una película del siglo XVIII, ese siglo ha sido interpretado de tantas formas que tienes cuarenta caminos, como por ejemplo todas las interpretaciones de pinturas, de grabados... Te sirven como elementos de valoración y puedes decir que unos no te interesan y otros sí. Pero en la época actual, ¿cómo la valoras? No tienes distancia" (GOROSTIZA, 2001:368).

Un caso significativo a la hora de reproducir las manifestaciones artísticas del pasado es el empleado por la productora española C.I.F.E.S.A., en cuyas películas del ciclo histórico se usaban unas referencias formales que no eran las imágenes contemporáneas a la época en que se desarrollaban sus argumentos, sino las de la pintura histórica del siglo XIX, por ejemplo para Locura de amor, dirigida por Juan de Orduña en 1948, no se buscó en los códices 


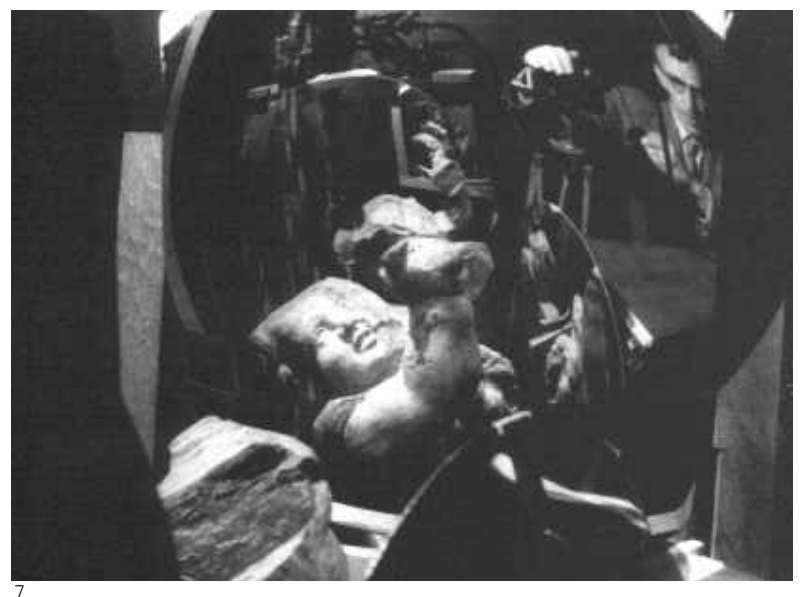

de la época, sino que se eligió directamente a un pintor del diecinueve, se reprodujeron los ambientes y el vestuario de los cuadros pintados por Francisco Padilla. Esto no sucedia por desconocimiento de los decoradores o los figurinistas, sino porque no importaba tanto la fidelidad histórica como la imagen que tenía el público de la época en la que sucedía la acción, una imagen tomada de la pintura del siglo pasado difundida a través de su reproducción en libros y revistas.

Sin embargo, no es necesario copiar la realidad en una película de ficción para que sea más verídica, casi siempre las recreaciones de esa realidad sirven para narrar una historia, mejor que si se hubiese copiado fielmente un edificio o una obra de arte. Hay que tener en cuenta que, por ejemplo, la capital de Italia de Federico Fellini reconstruida en Cinecittà para Roma (Roma, 1972) es más real que la de algunas películas neorrealistas, rodadas en las calles de la ciudad.

No se debe olvidar que en esta segunda forma de representación del patrimonio se debe incluir un nuevo método, que no es estrictamente cinematográfico, pero sí tiene relación con la imagen en movimiento. Se trata de las representaciones hechas con medios digitales, las infografías que reconstruyen edificios que no se llegaron a construir, los desaparecidos, o los modificados, como la Mezquita de Córdoba antes de la intervención cristiana. La novedad de estas construcciones virtuales con respecto al cine radica en que el usuario elige el recorrido que desea seguir para transitar por el edificio, escogiendo incluso puntos de vista que serian imposibles de tener en la realidad.

En fin, no se puede dudar que el cine, por sus características especiales que aúnan una técnica peculiar con la representación artística, es un lugar de referencias e influencias mutuas con las otras manifestaciones artísticas, y en ese sentido es único y diferente a las otras seis llamadas bellas artes.

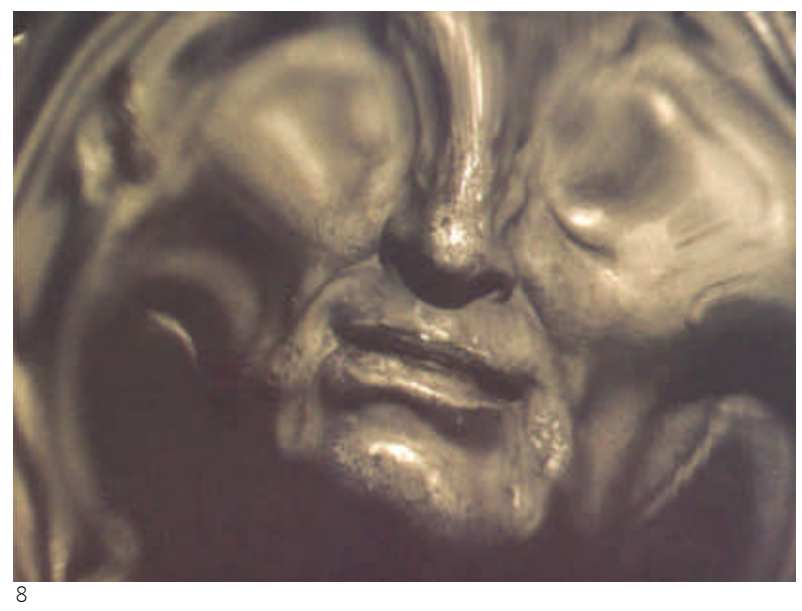

\section{Bibliografía}

BORDE, R. (1991) Los archivos cinematográficos. Valencia: Filmoteca Generalitat Valenciana, 1991

CANUDO, R. (1923) Manifeste des Sept Arts. La Gazette des sept arts, n² 2, 25 de enero de 1923, p. 2.

GEDULD, H. M. (ed.) (1981) Los escritores frente al cine. Madrid: Fundamentos, 1981

GOROSTIZA, J. (2001) La arquitectura de los sueños. Alcalá de Henares: 31 Festival de Cine, 2001

MALLET-STEVENS, R. (1925). Cahiers du Mois, n 16-17, 1925, pp. 95-98

MARINETTI, F. T.; CORRA, B.; SETTIMELLI, E.; GINNA, A.; BALLA, G.; CHITI, R.; (1916) La Cinematografía futurista. L'Italia futurista, n 9 , septiembre de 1916

MÜNSTERBERG, H. (1980) Film. II cinema muto nel 1916. Parma: Pratiche, 1980

\section{Notas}

${ }^{1}$ Véase UNSAIN, J. M. (1988) Nemesio Sobrevila, peliculero bilbaino. San Sebastián: Filmoteca Vasca, 1988, y FERNÁNDEZ COLORADO, L. (1994) Nemesio Sobrevila o el enigma sin fin. San Sebastián: Filmoteca Vasca, 1994.

${ }^{2}$ Para los arquitectos que trabajaron como directores artísticos en nuestro cine véase GOROSTIZA, J. (1997) Directores artisticos del cine español. Madrid: Filmoteca Española / Cátedra, 1997.

${ }^{3}$ Véase RAMíREZ, J. A. (1986) La arquitectura en el cine. Hollywood, la Edad de Oro. Madrid: Hermann Blume, 1986.

${ }^{4}$ Véase WALKER, J. A. (1993) Art \& Artists on Screen. Mánchester: Manchester University Press, 1993. Especificamente para los pintores: ORTIZ, A; PIQUERAS, M. J. (1995) La pintura en el cine. Cuestiones de representación visual. Barcelona: Paidós, 1995, pp. 129-165. y para Ios arquitectos: GOROSTIZA, J. (1997) La imagen supuesta, arquitectos en el cine. Barcelona: Fundación Caja de Arquitectos, 1997, pp. 49-55. 